\title{
確率過程論に基づいた降雨流出過程における 不確実性評価の理論的枠組の提示 A NEW THEORETICAL FRAMEWORK OF UNCERTAINTY ESTIMATION IN RAINFALL-RUNOFF PROCESS BASED ON THE THEORY OF STOCHASTIC PROCESS
}

\author{
吉見和紘 1 - Chao-Wen WANG ${ }^{1}$ - 山田正 $2 \cdot$ 山田朋人 3 \\ Kazuhiro YOSHIMI, Chao-Wen WANG, Tadashi YAMADA \\ and Tomohito J. YAMADA
1学生会員 工修 中央大学理工学研究科都市環境学専攻（干112-8551 東京都文京区春日1-13-27）
2フェロー会員 中央大学教授 理工学部都市環境学科（干112-8551 東京都文京区春日1-13-27）
3 正会員 北海道大学准教授 大学院工学研究院環境フィールド工学部門
（ (060-8628 北海道札幌市北区北13条西8丁目）

\begin{abstract}
The purpose of this study is to clarify the effect of uncertainty in the rainfall-runoff process. Though we have performed runoff analysis deterministically in the past, the uncertainty in the rainfall-runoff process is quantified stochastically through the introduction of the theory of stochastic process. We purpose the theoretical framework to evaluate the uncertainties using the relationship among Langevin equation, stochastic differential equation (SDE) and Fokker-Planck equation (FPE), because the lumped rainfall-runoff model is described by ordinary differential equation. That is, it is attributed to the similarity of structure between the lumped model and Langevin eq. or SDE. As a result, we provide a new perception into decision-maker in flood. Moreover, we theorize a new framework regarding reliability analysis with the distribution of water level as external force and the failure probability of levee as resistance.
\end{abstract}

Key Words : uncertainty, Langevin equation, stochastic differential equation, Fokker-Planck equation, runoff analysis

\section{1. はじめに}

流出解析では，対象とする地域特有の地質・土質状 態・植生の有無や種類, 山地・都市域等の多様な土地利 用をモデリング (理論化) し，降雨データを入力として， 流量・水位を決定論的に算出することが一般的である. 流出解析の入力として降雨データを用いるが，降雨デー タは多種多様であり，観測方法の違いや観測場所等に よって，降雨データの時間分解能，空間分布は異なる. 例えば，観測手法には，地上雨量計を用いた方法やCバ ンドレーダ，Xバンドレーダによるものがある．強降雨 強度を示す線状降水帯やゲリラ豪雨等の局所的な降雨の 観測には国土交通省が近年配置を推進してきた XRAIN(XバンドMPレーダ網)による観測が適しており， 空間分解能は $250 \mathrm{~m} \times 250 \mathrm{~m}$ ，時間分解能は1分である．原 理的には，同一波長でかつ水平・鈆直方向の電波を使う ことで，落下中の降水粒子の情報を捉え，降雨強度を精 密に測定するというものである。レーダ雨量計を用いた 降雨観測の精度向上により，これを用いた降雨の短時間 予測手法の開発や洪水汇濫予測手法の開発等の研究が精
力的に行われている. しかし, 降雨は時空間的に分布し ており，単に「雨をはかる」と言っても上述の通り，多 種多様な方法がある。観測手法ひとつ取っても，地上に 到達した雨滴を転倒マスで測って降雨強度換算するのか, 上空の雨滴をレーダで捕捉して降雨強度換算するのかに よって，同一の降雨イベントのハイエトグラフを描いた としても值は変わってくる. 加えて, それぞれの方法に おいて観測誤差が内包されているのが常である。これは， 降雨観測に限った話ではなく, 自然現象を観測する際に 常に付きまとう問題である. 我々の認識には限界がある 事を痛感させられるとともに，このような不確定・不確 実な現象をどのように取扱うべきかを考えざるを得ない．

本論文ではこれらの水文諸量における不確定性・不確 実性を扱うものであるが，入力值（流出現象で言えば降 雨強度）の不確定性・不確実性が出力值（流量・水位） に与える影響を, 流出計算の基礎式の確率微分方程式と しての記述，確率微分方程式とFokker-Planck方程式の対 応関係を用いて, 確率過程論的に明らかにする.

水文過程における不確実性の評価のために，水文モデ ルとFokker-Planck方程式の関係性を導入した研究として, 
Cayar and Kavvas ${ }^{1}$ の地下水流れへの応用例がある.これ は，2次元のBoussinesq方程式をLie郡論で常微分方程式 型のシステムに変換し，そのシステムを，キュミュラン 卜展開定理を通してFokker-Planck方程式型に変換する理 論展開であり, 本研究における基礎式の確率微分方程式 型での定式化，支配方程式のFokker-Planck方程式の導出 過程が本質的に異なる。一方, Supraba and Yamada ${ }^{2}$ は, 著者らが既往の研究3)で提示した確率過程論を導入した 不確実性評価手法と同様の理論的枠組を用いて，システ ムの入力である降雨データの空間的な不確実性に着目し, 流域の保水能と降雨パターンに起因寸る不確実性がピー ク流出高の不確実性へ及ぼす影響を評価している.

また，上述の著者らの既往の研究では，本論文と同様 に流出解析に確率過程論を導入し，降雨の不確実性が流 量・水位一及ぼす影響を明らかにする理論的枠組を提示 しているが，論文掲載後も著者間で議論を重㸚るうちに， 流出計算手法と確率微分方程式との関連付けに際して, 対応する方程式間での次元の不一致，かつ理論的に説明 が不十分な部分があるとの見解に至った．そのため，本 論文ではその内容を補完するとともに，新しい理論的な 枠組みを提示する.

\section{2. 伊藤の確率微分方程式とFokker-Planck方程式}

1905年にEinstein ${ }^{4}$ は，Brown運動する微粒子は熱運動 する分子の不規則な衝突に起因することを理論的に示し た. 1920年代にはWienerによってその現象が数理的モデ ルとして発表されている。また，1910年代には，

Fokker ${ }^{5}$, Planck ${ }^{6}$ によって, Langevin方程式 7 から確率密 度関数の時間発展に関する偏微分方程式 (Fokker-Planck 方程式）が導かれている。これらの研究には，当然なが らEinsteinのBrown運動の論文が引用されている．1930年 代になると，Fokker-Planck方程式はKolmogorov ${ }^{8}$ によっ て一般化され，Markov過程の場合にFokker-Planck方程式 が成立する事が示されている，これは即ち，Kolmogorov の前向き方程式として知られるものである.

一方で1940 年代, 伊藤清 ${ }^{9}$ は, 確率解析学を創始し, 非決定論的な現象を記述できる確率微分方程式を提唱し た.これにより，Brown運動のような微粒子が媒質中で 見せる不確実な運動を形式的に表現し得るとして Langevin方程式が確率微分方程式として記述された．同 時に, 数学的に厳密な意味付けが行われることとなり, 確率解析的に解くことが可能となった。 このように, 確 率解析学の礎が築かれ, 現代においては数学分野のみな らず, 物理学, 工学, 経済学の各分野において広く応用 されている. 物理学や工学の分野では, 確率微分方程式 で記述されるひとつの確率過程に着目寸るよりも，その 確率分布を求めることで不確かさを求める事が一般的で ある.

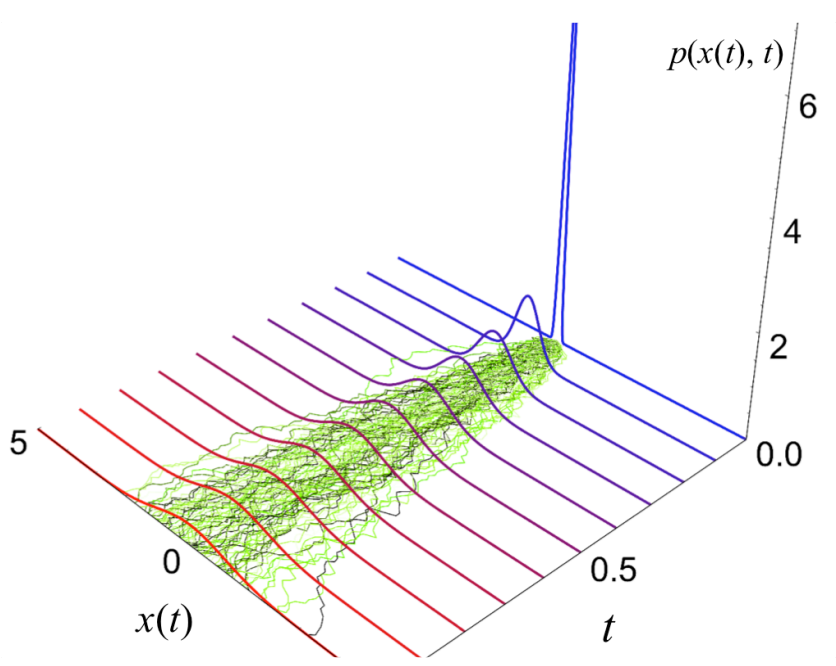

図-1 確率微分方程式とFokker-Planck方程式の関係. （簡単な例 として, 確率微分方程式 $\mathrm{dx}(\mathrm{t})=\sigma \mathrm{dw}(\mathrm{t})$ (:Wiener 過程) とそ れに対応するFokker-Planck方程式の計算例を示す. 一本一 本の確率経路に対して，それぞれの時間に対応する確率密 度関数が描かれており, 両者は同一の現象を異なる視点か ら記述した方程式であることがわかる. )

以下では確率微分方程式とFokker-Planck方程式の数学 的な対応関係について簡単に説明する.

\section{（1） 伊藤の確率微分方程式}

一次元空間において, 時系列 $x(t)$ の微分 $d x$ が次式に 従って動いている時, この時系列 $x(t)$ の動きを伊藤過程 という.

$$
d x(t)=y(x(t), t) d t+z(x(t), t) d w(t)
$$

ここに, $y(x(t), t), z(x(t), t)$ は時間 $t$ 之時系列 $x(t)$ の任意の 関数である.また, $d w(t)$ はWiener過程 $w(t)$ の微小時間変 化量であり, 平均 0 , 分散 $d t$ の正規分布に従っている. 伊藤過程とは一般化したWiener過程の定数部分を $x$ とtの 任意関数でより一般化したものである.このように，空 間座標 $x(t)$ の増分が上式の様に右辺のドリフト項と確率 増分項で表されるとき, 上式を伊藤の確率微分方程式と いう.

\section{(2) Fokker-Planck方程式}

Fokker-Planck方程式の導出は確率微分方程式から導く 方法や, Chapman-Kolmogorov方程式からmaster方程式を 経てFokker-Planck方程式を導出する方法等があるが，こ れに関しては文末の文献10)を参照されたい. 以下に示す (2)式は(1)式に対応するFokker-Planck方程式である.

$$
\begin{aligned}
& \frac{\partial p(x(t), t)}{\partial t}= \\
&-\frac{\partial y(x(t), t) p(x(t), t)}{\partial x} \\
&+\frac{1}{2} \frac{\partial^{2} z(x(t), t)^{2} p(x(t), t)}{\partial x^{2}}
\end{aligned}
$$


両者の関係を図化すると，図一1のようになる，これら は，同一の現象を異なる2つの視点から捉えた式であり， 確率微分方程式がある確率過程 $x(t)$, ひとつひとつの過 程を表現しているのに対して, 確率経路の確率密度関数 の時間発展 $p(x(t), t)$ を満たす偏微分方程式がFokker-Planck 方程式と呼ばれる. 確率微分方程式は，決定論的項と確 率論的項とで表現されるものであり，(1)式の右辺第一項 が決定論的，右辺第二項が確率論的な軌跡を表現する. そして，これら二項の $y(x(t), t), z(x(t), t)$ は(2)式のFokkerPlanck方程式の右辺第一項と第二項の $y(x(t), t), z(x(t), t)$ に それぞれ対応している。

次章で示す流出計算の基礎式と本章で示した確率微分 方程式の関係性から, 流出高に関するFokker-Planck方程 式を得ることが出来る.

\section{3. 流出計算の基礎方程式の概要}

\section{（1）降雨流出計算の基礎式}

山田 ${ }^{11)}$ は，単一斜面に対して幅広矩形断面を想定し， 連続式と運動則を基礎式として，(3)式に示す貯留型の降 雨流出計算手法を示している.

$$
\frac{d q_{*}}{d t}=a_{0} q_{*}^{\beta}\left(r(t)-q_{*}\right)
$$

ここに，q*(t)は流出高 $[\mathrm{mm} / \mathrm{h}]$ である． $r(t)$ は有効降雨強度 $[\mathrm{mm} / \mathrm{h}]$ であり, 流出計算の入力值となる. 以下，入力降 雨強度という。また，

$$
a_{0}=(m+1)\left(\frac{\alpha}{L}\right)^{\frac{1}{m+1}}, \quad \beta=\frac{m}{m+1}
$$

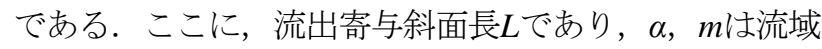
特性を表すパラメータとして。

$$
\alpha=\frac{k_{s} i}{D^{\gamma-1} w^{\gamma}} \quad, \quad m=\gamma-1
$$

で与えられる。これらの土壤・地形特性を示す流出パラ メータ $\alpha$ と $m$ の值に関して志村ら ${ }^{12)}$ は，不飽和浸透理論と Kinematic Wave法の式展開を比較する事により，(5)式で 決定できる事を示している.

ここに, $i$ : 斜面勾配, $D$ : 表層土層厚 $[\mathrm{mm}], \gamma:$ 土䁃 の透水性を表す無次元パラメータ, $k s$ : 飽和透水係数 $[\mathrm{mm} / \mathrm{h}], w$ : 有効空隙率であり, $w=\theta s-\theta r(\theta s$ : 飽和含水 率, $\theta r$ : 残留含水率)で定義される. また，抵抗則 $m$ は無 次元パラメータであり, $\alpha$ の次元は $m$ の值に依存する.

(3)式が一般化された単一斜面からの降雨流出の基礎式と なる.

\section{（2） 貯留関数法との比較}

木村の貯留関数法 ${ }^{13)}$ は計算の容易性や洪水の再現性が 高いことから河川計画に多用されている．以下に貯留関
数法の理論の概要を示す.

貯留関数法では，(6)式に示す連続式で対象とする流域 の貯留高と降雨流出関係を表している.

$$
\frac{d S}{d t}=r(t)-q_{*}
$$

ここで，降雨と流量の実測值から貯留量 $S$ を求めた場 合, 貯留量流量曲線が二価性を示すことを根拠として, 木村は遅れ時間 $T_{d}$ を考慮して流出高を $q_{*}\left(t+T_{d}\right)$ で表現して いる. 貯留量流量関係を一本の曲線で近似して，以下の 式で表現している.

$$
S=K q_{*}^{P}
$$

この貯留量 $S$ と流出高 $q_{*}$ の運動式と連続式を整理する ことにより，

$$
\frac{d q_{*}}{d t}=\frac{1}{K P} q_{*}^{1-P}\left(r(t)-q_{*}\right)
$$

を得る。この式は(3)式で示した単一斜面における降雨流 出の基礎式と全くの同型である.

貯留関数法では，(7)式によって貯留量流量関係が近似 されることで流出パラメータが少なくて済む反面，概念 的な扱いが導入されていることから，流出パラメータの 物理的意味を評価することが難しい，一方で，単一斜面 における降雨流出の基礎式では，単位幅流量 $q$ を変数分 離形の近似式で表す事によって，物理的な仮定を与えて いるため, 流出パラメータを(5)式のように物理的に表現

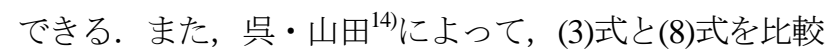
することにより, 貯留関数法における流出パラメータ $K$ 及びPは，

$$
P=\frac{1}{m+1}, \quad K=\left(\frac{\alpha}{L}\right)^{P}
$$

と表わせる事が示されている，また，本来，貯留関数法 は斜面長の短い単一斜面からの斜面流下方向流れを対象 として導出，適用されるものである事とその物理的意義 が明らかにされている.

(3)式と(8)式の常微分方程式は全くの同型であるが,流 出パラメータの物理性や扱い易さから, 本論では前者を 流出解析の基礎式として用いることとする.

\section{4. 確率過程論の流出解析への導入}

本章では，流出計算の基礎式である(3)式と伊藤の確率 微分方程式(1)式，それに対応するFokker-Planck方程式(2) 式の関係を示す.

\section{（1）貯留型の流出計算手法と確率微分方程式の関係}

(3)式は，流出高 $q$ *関する一階の常微分方程式であり, 差分形式で表現すると以下のようになる.

$$
d q_{*}=a_{0} q_{*}^{\beta}\left(r(t)-q_{*}\right) d t
$$


ここで，入力降雨強度 $r(t)$ が，各時刻において，ある平 均值とその平均值周りにホワイトノイズとして微小な乱 れ成分 $r^{\prime}(t)$ が分布していると仮定して,

$$
r(t)=\bar{r}(t)+r^{\prime}(t)
$$

で与えられるとすると，(10)式は以下のようになる.

$$
d q_{*}=a_{0} q_{*}^{\beta}\left(\bar{r}(t)-q_{*}\right) d t+a_{0} q_{*}^{\beta} r^{\prime}(t) d t
$$

ここで，(12)式を確率微分方程式の形に読み替えれば， 以下に示す流出高に関する確率微分方程式を得る.

$$
d q_{*}=a_{0} q_{*}^{\beta}\left(\bar{r}-q_{*}\right) d t+a_{0} q_{*}^{\beta} \sigma \sqrt{T_{L}} d w
$$

ここに，右辺第一項が決定論的な項，右辺第二項が確率 論的な項を表しており， $d w$ はWiener過程に従う時系列 $w(t)$ の微小時間変化量であり正規分布 $N(0, d t)$ に従う。こ こで， $\sigma \sqrt{T_{L}} d w$ として表現できるのは，流出計算の基 本式(3)式とLangevin方程式の比較及びG.I.Taylorの拡散理 論 ${ }^{15)}$ から説明することができる．以下にその概要を示す，

\section{（2）流出高に関するFokker-Planck方程式}

(14)式に示す一般的なLangevin方程式と Fokker-Planck 方程式の関係を示す.

$$
\frac{d v}{d t}=K(v)+\beta(v) R(t)
$$

のランダムな摇動力 $R(t)$ はホワイトノイズであり ,

$$
\begin{gathered}
\langle R(t)\rangle=0 \\
\langle R(t) \cdot R(s)\rangle=D(v) \delta(t-s)
\end{gathered}
$$

という性質を満たしている．ここに， $\delta$ はディラックの デルタ関数である．伊藤解析で考えれば，(14)式に対応 するFokker-Planck方程式は，

$$
\begin{aligned}
& \frac{\partial p(v, t)}{\partial t} \\
& \quad=-\frac{\partial K(v) p(v, t)}{\partial v}+\frac{1}{2} \frac{\partial^{2} \beta(v)^{2} D(v) p(v, t)}{\partial v^{2}}
\end{aligned}
$$

となる ${ }^{16)}$ 。また，確率微分方程式との関係は以下のよ うになる。

$$
d v=K(v) d t+\beta(v) \sqrt{D(v)} d w(t)
$$

上記の関係性に従って，(12)式を改めてLangevin型の 方程式として考え，それに対応するFokker-Planck方程式 を考えることで降雨流出の基礎式と確率微分方程式の関 係を明らかにすることができる.

まず，(12)式はLangevin方程式型で記述すると，

$$
\frac{d q_{*}}{d t}=a_{0} q_{*}^{\beta}\left(\bar{r}(t)-q_{*}\right)+a_{0} q_{*}^{\beta} r^{\prime}(t)
$$

となる. 右辺第一項が決定論的項，第二項が確率論的項 である。ここで注意しなければならない重要なポイント は，Langevin方程式と違い，(19)式の第二項自身が摇動 力なのではなく,$r^{\prime}(t)$ がホワイトノイズであるという点 である。一般的なLangevin方程式では摇動力そのものが 速さの次元を時間微分した次元を持つが，(19)式中で, これと同意義の量，つまり速さを時間で微分した次元の ものを考えるのであれば，(19)式の第二項は以下のよう に書き改められる.

$$
a_{0} q_{*}^{\beta} r^{\prime}(t)=\underbrace{a_{0} q_{*}^{\beta} T_{L}}_{\text {無次元量 }} \underbrace{\frac{r^{\prime}(t)}{T_{L}}}_{\text {速さ時間の次元 }}
$$

$T_{L}$ は降雨の乱れ成分に関する時定数である. また, $r^{\prime}(t)$ はホワイトノイズと仮定しているため,

$$
\begin{gathered}
\left\langle r^{\prime}(t)\right\rangle=0 \\
\left\langle r^{\prime}(t) \cdot r^{\prime}(s)\right\rangle=D_{r} \delta(t-s)
\end{gathered}
$$

である.ここで, G.I.Taylorの拡散理論における速度の乱 れ成分を降雨の乱れ成分 $r^{\prime}(t)$ の問題に置き換えて考える. エルゴード性を仮定すれば，アンサンブル平均と時間平 均は等しいので,

$$
\left\langle r^{\prime}(t)\right\rangle=\bar{r}^{\prime}(t)
$$

が成立し，拡散係数 $D_{r}$ は，s=t-てとして，

$$
\begin{aligned}
D_{r} & =\int_{0}^{t} \overline{r^{\prime}(t) r^{\prime}(t-\tau)} d \tau \\
& =\overline{r^{\prime 2}}(t) \int_{0}^{t} R_{L}(\tau) d \tau
\end{aligned}
$$

となる.ここに，

$$
R_{L}(\tau)=\overline{r^{\prime}(t) r^{\prime}(t-\tau)} / \overline{r^{\prime 2}}(t)
$$

は自己相関係数である.また，

$$
\int_{0}^{\infty} R_{L}(\tau) d \tau=T_{L}
$$

であり， $T_{L}$ は先に述べた時定数である.よって, $r^{\prime}(t) に$ 関する拡散係数 $D_{r}$ は時定数 $T_{L}$ を用いて,

$$
D_{r}=\overline{r^{\prime 2}}(t) \cdot T_{L}
$$

と表せる．また， $r^{\prime}(t)$ がホワイトノイズであると仮定し ているので,

$$
\overline{r^{\prime 2}}(t)=\sigma^{2}
$$

である.よって， $r^{\prime}(t)$ に関する拡散係数 $D_{r}$ は,

$$
D_{r}=\sigma^{2} \cdot T_{L}
$$

と表せる。ここに， $\sigma$ は $r^{\prime}(t)$ の標準偏差である。

以上から，(19)式に対応するFokker-Planck方程式は

$$
\begin{aligned}
\frac{\partial p\left(q_{*}, t\right)}{\partial t}= & -\frac{\partial a_{0} q_{*}^{\beta}\left(\bar{r}-q_{*}\right) p\left(q_{*}, t\right)}{\partial q_{*}} \\
& +\frac{1}{2} \frac{\partial^{2}\left(a_{0} q_{*}^{\beta} \sigma \sqrt{T_{L}}\right)^{2} p\left(q_{*}, t\right)}{\partial q_{*}^{2}}
\end{aligned}
$$

となる．また，上記の過程から(30)式に対応する確率微 分方程式は(13)式となることが明らかである.

この(30)式が流出高の確率密度関数の時間発展を記述 

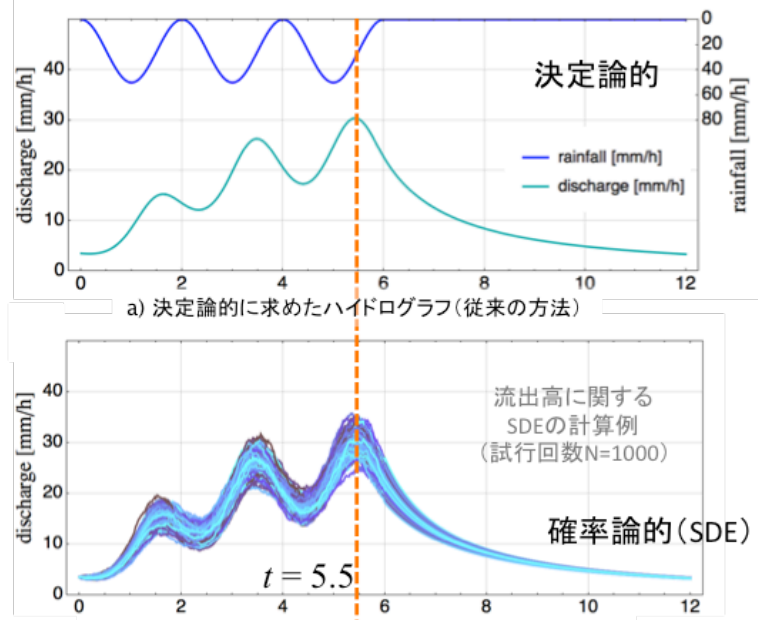

b) SDEを解いて求めたハイドログラフ(試行回数1000回)

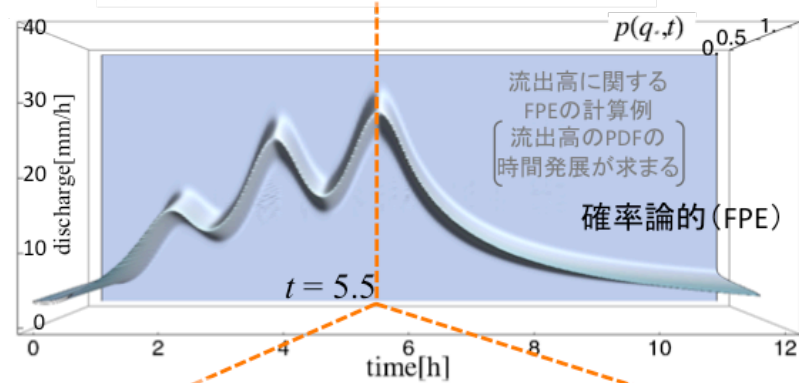

c) FPEを解いて求めたPDFの時間発展

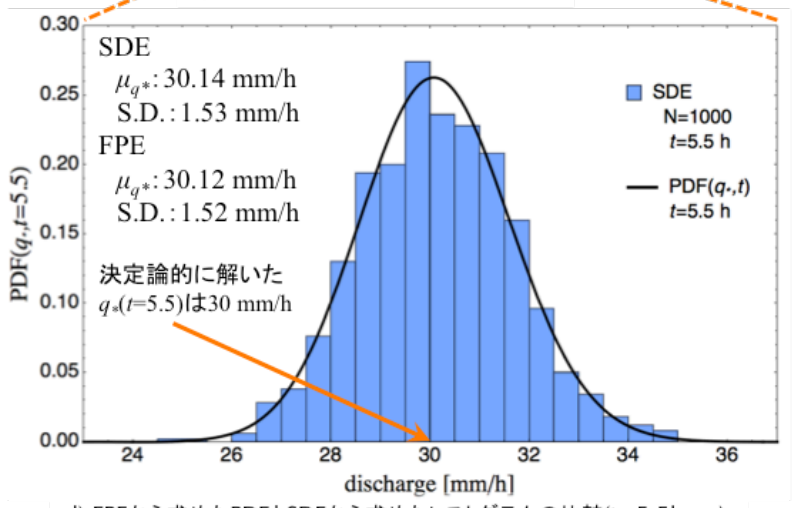

d) FPEから求めたPDFとSDEから求めたヒストグラムの比較 $(\mathrm{t}=5.5$ hour $)$

図-2 決定論及び確率論的に求めたハイドログラフと流出量の 確率密度関数の時間発展, 及び確率微分方程式 (SDE) か ら求めたヒストグラムとFokker-Planck方程式(FPE) で求 めた確率密度関数の比較 $\left(\sigma=5 \mathrm{~mm} / \mathrm{h}, \mathrm{T}_{\mathrm{L}}=1 / 6 \mathrm{~h}\right.$ である.

a）は, Sin波形の降雨強度を入力としている. b) はその 入力降雨強度に微小な乱れr' (t) としてホワイトノイズ が加わった降雨強度を入力としてSDEを解いている（SDE の計算試行回数 $\mathrm{N}=1000)$ ． C) は，初期条件として極めて 分散の小さい正規分布を与え, 降雨の標準偏差 $\sigma$, 時定 数厂 は一定値としてFPEを解いている. d) は, $\mathrm{t}=5$. 5hour 時点の $\mathrm{q}_{*}$ のヒストグラムで, SDEとFPEの計算結果から得 られる平均と標準偏差はそれぞれ，SDE : 平均 $30.14 \mathrm{~mm} / \mathrm{h}$, 標準偏差 $1.53 \mathrm{~mm} / \mathrm{h}, \mathrm{FPE}$ : 平均 $30.12 \mathrm{~mm} / \mathrm{h}$, 標準偏差 1. 52mm/hであり，両者の差は極めて小さい. )

するFokker-Planck方程式である．本論文では，システム に入力される雑音が最も不確実な場合を想定してホワイ トノイズを仮定し理論展開しているが，雑音が有色雑音
の場合でも，高次のFokker-Planck方程式を導出すること で，本理論の枠組み内でシステムの出力の不確実性を評 価できる.

\section{5. 計算結果}

従来の決定論的な流出解析の結果と比較する形で，入 力の不確定性・不確実性が及ぼす出力の不確かさを評価 する手法を示す．以下では，流出高の確率微分方程式の 解及びFokker-Planck方程式の解を示す.

図-2に示すのが，a)決定論的に流出計算（従来の流出 計算）した結果，b)流出高についての確率微分方程式を 用いた計算結果及びc)流出高についてのFokker-Planck方 程式から得られる計算結果である。いずれの計算におい ても，入力降雨強度は，ピーク降雨強度が $50 \mathrm{~mm} / \mathrm{h}$ の 1 周 期 2 時間のSin波形の降雨を与えており， $\sigma=5 \mathrm{~mm} / \mathrm{h}$ とし て一定值， $T_{L}=1 / 6 \mathrm{~h}$ を与えてる。 $\sigma$ は，降雨強度の変 化に伴って，時間ないし降雨強度の関数として表せるは ずであるが，本論では確率過程論に基づく，流出過程に おける不確実性評価の枠組みの提示を主題としているた め，この点は参考文献に譲り，最も単純な場合による結 果を示している. 図-2 b)の確率微分方程式を解いた計算 の試行回数は1000回であり, 図-2 d)の確率微分方程式 から得た結果のヒストグラムとFokker-Planck方程式から 得た確率密度関数を, 流出高ハイドログラフのピーク付 近5.5hour時点において比較している．また，図-2 d)のヒ ストグラムと確率密度関数の比較からも確率微分方程式 とFokker-Planck方程式が同一の現象を記述していること がわかる．常微分方程式型の貯留型の流出計算手法を確 率微分方程式として解いた計算結果と理論的に導き出さ れた確率微分方程式に対応するFokker-Planck方程式を解 いた解が一致しており，流出過程を確率過程と考えた場 合に容易に任意時間の確率密度関数を求められる事がわ かる。

\section{6. まとめ}

降雨流出過程における不確定性・不確実性を評価する ために，流出解析に確率過程論を導入し，入力が持つ不 確定性・不確実性が出力に及ぼす影響を明らかにする理 論的枠組を示した.

具体的には，常微分方程式型の降雨流出の基礎式は， 降雨が決定論的な成分と確率論的な成分で構成されると 考える事で，Langevin型の方程式として考えることがで きる，さらに入力に関する雑音に着目し，降雨強度が $\mathrm{mm} / \mathrm{h}$ の次元であることから, 速さの次元を持つ物理量 そのものが正規ホワイトノイズに従う事と仮定すれば, 伊藤の確率微分方程式として取り扱えること，及びそれ 


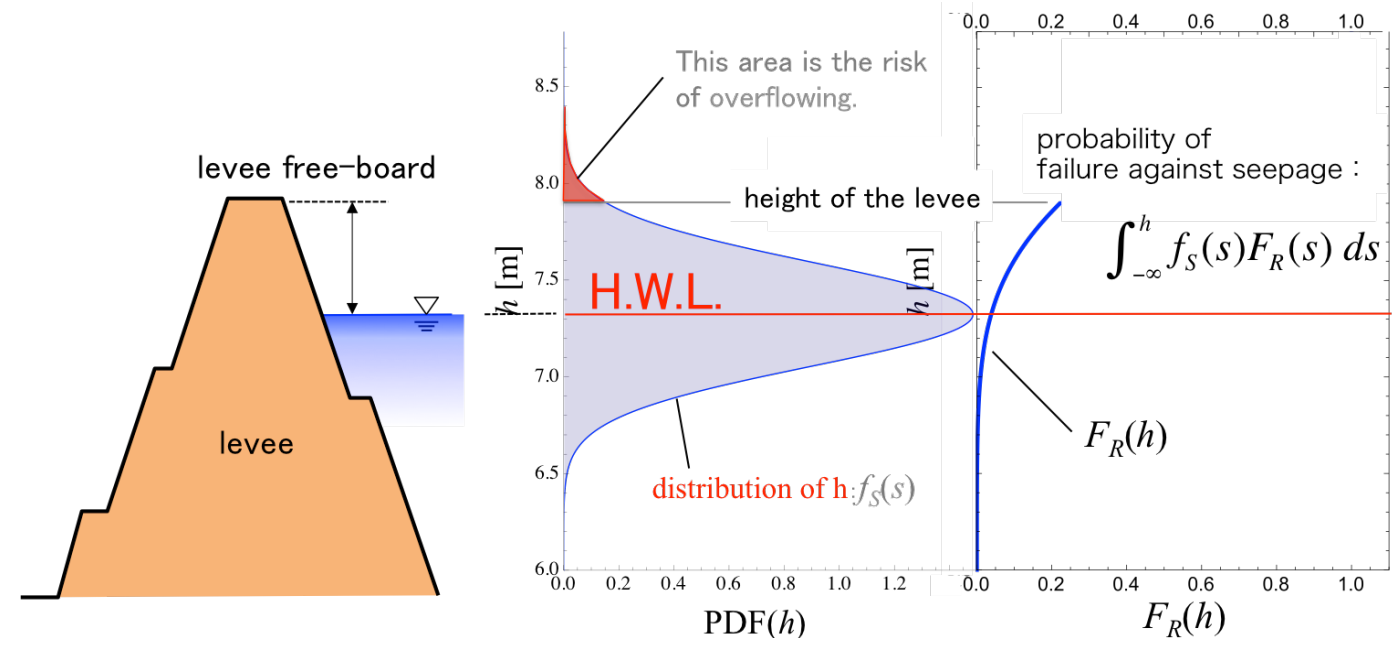

図-3 堤防と水位のイメージ図(左)，水位の確率分布 $\mathrm{fs}(\mathrm{h})\left(\right.$ 中) と堤防の破壊確率 $F_{\mathrm{R}}(\mathrm{h})(\text { 右 })^{17)}$. (水位の確率分布を示す図中の赤 い領域の面積は越水確率を表している. また，右図の青い曲線はFR (h) は各水位における越水確率を算出し内挿した関数で ある. 両者をそれぞれ外力と耐力として信頼性解析を行うことで, ある水位までに堤防がすべり破壊する確率を算出でき る. さらに破壊確率と越水確率を比較することができる.)

に対応するFokker-Planck方程式が存在することを示した. つまり，流出高についてのFokker-Planck方程式を得るこ とが出来た。これを解けば，降雨に不確実性がある場合 の流出高についての確率密度関数の時間発展を知ること ができる.

例えば，この成果は流量や水位の不確実性評価につい ても応用できる. 特に水位の分布は, 洪水時に避難判断 をするタイミングを議論する素材として極めて有用であ るし，図-3に示すように，水位に対する堤防の破壊確率 を求めることができれば，水位の分布を外力，堤防の破 壊確率を耐力として，信頼性解析を行うことができる.

内閣府は平成26年4月に「避難勧告等の判断・伝達マ ニュアル作成ガイドライン」を改訂しており，避難勧告 等の判断基準の見直しを行なっている。 それを受け国土 交通省は，洪水時の情報提供について，「越水」「浸 透」「侵食」に分けて避難勧告等の判断基準を設定して おり，水位の確率分布から得られる越水確率や水位に対 する堤防の破壊確率（浸透破壞）の算定が可能となれば, 有益な知見を提供することができると考えている.

謝辞：本研究の一部は，文部科学省科学研究費補助金 (基盤A，課題番号26249072)の支援を受けて実施された. ここに記して謝意を表します。

\section{参考文献}

1) Cayar, M. and Kavvas, M.L.: Symmetry in Nonlinear Hydrologic Dynamics under Uncertainty: Ensemble Modeling of 2D Boussinesq Equation for Unsteady Flow in Heterogeneous Aquifers, Journal of Hydrologic Engineering, 14(10), 2009.

2) Supraba, I. and Yamada, T.J.: Uncertainty of Peak Runoff Height Associated with Uncertainty of Water Holding Capacity and Rainfall Pattern, Journal of Japan Society of Civil Engineers, Ser.G (Environmental Research), Vol.71, No.5, pp.17-22, 2015.
3) 吉見和紘, 山田正, 山田朋人: 確率微分方程式の導入による 降雨流出過程における降雨の不確実性の評価, 土木学会論文 集B1(水工学), Vol.71, No.4, 259-264, 2015.

4) A. Einstein: On The Movement of Small Particles Suspended in Stationary Liquids Required by The Molecular-Kinetic Theory of Heat, Annalen der Physik, 17, 549-560, 1905.

5) 例えば, A. D. Fokker: Die mittlere Energie rotierender elektrischer Dipole im Strahlungsfeld, Ann. Phys. 348, 810-820, 1914.

6) 例えば, V. M. Planck: Über einen Satz der statistischen Dynamik und seine Erweiterung in der Quantentheorie, Sitzungberichte der Koniglich Preussischen Akademie der Wissenschften, 323-341, 1917.

7) P. Langevin: Sur la théorie du mouvment brownien, ComptesRendus de I'Académie des Sciences 146, 530-538, 1908.

8) A. Kolmogorov: Über die analytischen Methoden in der Wahrscheinlichkeitsrechnung, On Analytical Methods in the Theory of Probability, Mathematics and its Applications, 26, 448-451, 1931.

9) 伊藤清 : 確率論【現代数学(14)】, 岩波書店, 1953.

10)保江邦夫 : 数值確率解析入門, 朝倉書店, 2000.

11)山田正：山地流出の非線形性に関する研究，水工学論 文集，第 47 巻,pp.259-264, 2003.

12)志村光一，大原憲明，松本浩志，山田正: 水理計算に基づく 大規模河道網の洪水流出特性に関寸る研究，水文・水資源学 会誌, Vol.14, No.3, pp.217-228, 2001.

13)木村俊晃 : 貯留関数法による洪水追跡流出法，建設省土木 研究所, 1961.

14)吳修一, 山田正: 既往概念流出モデルの理論的導出, 水文・水資源学会誌, Vol.22, No.5, pp.386-400, 2009.

15)G. I. Taylor: Diffusion by continuous movements, Proceedings of the Royal Society A, 20, 196-211, 1921.

16)N. G. van Kampen: Stochastic Processes in Physics and Chemistry, North-Holland personal libraly, 2007.

17)Chao-Wen WANG，吉見和紘，辛島史嗣，山田正 : 降雨の不 確実性に基づく確率過程論を導入した堤防の信頼性評価, 土 木学会論文集G, Vol.71, No.5,pp.1-6, 2015.

(2015. 9. 30受付) 